\title{
ПЕРИОПЕРАЦИОННОЕ АНЕСТЕЗИОЛОГИЧЕСКОЕ ОБЕСПЕЧЕНИЕ

\author{
БОЛЬНЫХ С МОРБИДНЫМ ОЖИРЕНИЕМ
}

\begin{abstract}
Ожирение - важный фактор риска развития различных серьезных заболеваний, приводящих к физической дезадаптации, повышению смертности в популяции, по сравнению с группой людей с нормальной массой тела. Очевидные анатомические трудности, скрытые особенности физиологии и фармакокинетики анестезиологических препаратов создают определенные проблемы для анестезиолога в периоперационном периоде [21].
\end{abstract}

Ключевые слова: масса тела, морбидное ожирение, госпитализация, анестезия

\section{ОЖИРЕНИЕ И СИСТЕМА ДЫХАНИЯ}

Одной из наиболее опасных дисфункций респираторной системы у больных с морбидным ожирением является синдром сонного апноэ (ССА) [10]. Синдром характеризуется эпизодами ночного гипопноэ и апноэ, сопровождающихся гипоксемией, гиперкапнией, возрастанием системного и легочного артериального давления, нарушениями ритма сердца [26]. Перманентная гипоксемия приводит к развитию полицинемии, ишемической болезни сердца, легочной гипоксической вазоконстрикции и правожелудочковой недостаточности [39]. Надо иметь в виду, что многие средства, применяемые при общей анестезии, снижают тонус мышц глотки, угнетают сознание и провоцируют развитие ССА.

Предоперационная оценка состояния верхних дыхательных путей крайне важна для анестезиолога в аспекте предстоящей при проведении общей анестезии масочной вентиляции и последующей интубации трахеи. Необходимо оценить подвижность шеи, величину ее окружности, широту открывания рта, полноценность визуализации ротоглотки в соответствии с классификацией по Mallampati. Отмечена высокая корреляция между величиной окружности шеи более 60 cм, III-IV классом по Mallampati и трудной прямой ларингоскопией и соответственно интубацией трахеи [15]. Рутинное применение фибробронхоскопии для интубации трахеи в бариатрической хирургии не показано и должно быть резервировано для пациентов с реальными анатомическими проблемами.

Морбидное ожирение ассоциируется со снижением функциональной остаточной емкости легких, резервного объема выдоха и общей емкости легких, причем функциональная остаточная емкость легких снижается с возрастанием ИМТ [16]. Лапаротомия при ИМТ >30 кг/м² приводит к снижению ЖЕЛ на 40\% и более, тогда как у пациентов с нормальной массой тела редукция этого параметра не превышает 10\% [15].
Нарушение вентиляционно-перфузионных отношений с внутрилегочным шунтированием 10-25\%, по сравнению с 2-5\% у больных с нормальной массой тела, может приводить к выраженной и стойкой гипоксемии во время анестезии, обладающей эффектом увеличения внутрилегочного шунтирования [65]. Уже на этапе вводного наркоза у пациентов с ожирением развиваются ателектазы, еще более увеличивающие степень гипоксемии [46]. У лиц с морбидным ожирением, по сравнению с персонами с нормальной массой тела, существенно выше потребление энергии, следовательно, выше абсолютное потребление кислорода и продукция углекислого газа. Это обязательно следует учитывать при интерпретации мониторируемых уровней кислорода и $\mathrm{CO}_{2}$ на вдохе и выдохе при проведении ИВЛ во время анестезии, особенно ингаляционной с низким или минимальным потоком [15]. Уровень исходной гиперкапнии следует учитывать при проведени ИВЛ при анестезии. Не следует стремиться к нормокапнии, т. к. это может привести к вполне понятной дыхательной депрессии в постнаркозном периоде у пациентов с пониженной чувствительностью дыхательного центра к $\mathrm{CO}_{2}$, а именно этим и отличаются больные с морбидным ожирением, постоянно живущие в условиях гиперкапнии той или иной степени.

\section{ОЖИРЕНИЕ И СЕРДЕЧНО-СОСУДИСТАЯ СИСТЕМА}

В сравнении с людьми с нормальной массой, у пациентов с морбидным ожирением отмечаются более высокие в абсолютных цифрах показатели объема циркулирующей крови (ОЦК) и минутного объема сердца (МОС). При этом относительные показатели, отнесенные к единице поверхности тела, могут быть нормальными или даже сниженными [66]. Для пациентов с ИМТ более $40 \mathrm{\kappa r} / \mathrm{M}^{2}$ характерно увеличение спланхнического кровотока в среднем на 20\%, у $50 \%$ пациентов имеется умеренно выраженная артериальная гипертония, a y 5-10\% эта патология приобретает выраженный характер.

Многие пациенты с морбидным ожирением, особенно страдающие синдромом сонного апноэ, демонстрируют прогрессивное повышение легочного артериального давления, 
приводящего к развитию правожелудочковой недостаточности, периферическим отекам и печеночной дисфункции. При наличии признаков правожелудочковой недостаточности следует быть особенно осторожным при проведении инфузионной терапии, избегать избыточной нагрузки жидкостью, по возможности снижать пиковое давление и положительное давление в конце выдоха при проведении искусственной вентиляции легких [32]. При прогрессировании правожелудочковая недостаточность приводит к редукции сердечного выброса и становится угрожающим предиктором развития полиорганной недостаточности, на фоне которой сложно вести разговор о хирургическом лечении [46], так любое стрессовое воздействие (интубация трахеи, операция, послеоперационная боль) способно привести к декомпенсации сердечно-сосудистой системы.

Для достижения оптимального статуса сердечнососудистой системы перед большой травматичной операцией больные с гипертонией, нарушениями ритма сердца, гиперволемией, дизлипидемией должны иметь серьезную антигипертензивную поддержку [29]. Препараты группы «статинов» должны быть отменены за неделю до операции ввиду их миотоксического действия, повышающего риск развития рабдомиолиза, достаточно специфического осложнения бариатрической хирургии [27].

\section{ОЖИРЕНИЕ И АБДОМИНАЛЬНЫЕ ПРОБЛЕМЫ}

Ожирение характеризуется повышением интраабдоминального давления, что приводит к негативным сердечнососудистым изменениям (снижение жизненной емкости легких, аортокавальная компрессия). При достижении определенного уровня интраабдоминальная гипертензия может приводить к развитию абдоминального компартмент-синдрома, полиорганной, в т. ч. почечной, дисфункции и недостаточности [15]. Аспирация и развитие аспирационного пневмонита вполне реальны. Не стоит игнорировать такие эффективные профилактики регургитации и аспирации, как быстрая индукция в анестезию и прием Селлика. Поскольку риск аспирационных осложнений сохраняется и в ближайшем постнаркозном периоде, экстубацию трахеи следует выполнять при полном восстановлении сознания и мышечного тонуса.

\section{ОЖИРЕНИЕ И РИСК ВЕНОЗНОГО ТРОМБОЭМБОЛИЗМА}

Риск тромбоза глубоких вен ног и ТЭЛА у пациентов в бариатрической хирургии вдвое превышает аналогичный риск у больных с нормальной массой тела. Риск тромбоэмболических осложнений возрастает при длительной иммобилизации, сопровождающейся венозным стазом, полицитемии, нередко встречающейся у больных с морбидным ожирением, повышении интраабдоминального давления, сердечной недостаточности, снижении фибринолитической активности и повышении уровня фибриногена в плазме [10]. Следует отметить, что более трети, а по некоторым данным [59], 80\% тромбоэмболических осложнений регистрируется после выписки больного из стационара в течение 30 дней. Открытые опера- ции сопровождаются более высокой частотой тромбоэмболических осложнений, по сравнению с лапароскопическим

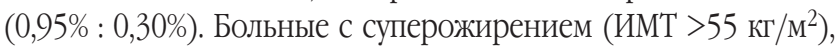
имеющие в анамнезе эпизоды тромбоэмболических осложнений, тяжелую варикозную болезнь ног, гиповентиляционный синдром, представляют группу особого риска развития тромбоэмболических осложнений. В определенных случаях следует рассматривать вопрос о превентивной имплантации CAVAфильтра [60]. Внедрение в практику рутинного применения гепарина для профилактики венозного тромбоэмболизма в бариатрической хирургии существенно снизило частоту осложнений [20]. Очевидно также, что профилактику ТЭЛА следует пролонгировать в послеоперационном периоде в

\section{Одной из наиболее опасных дисфункций респираторной системы у больных с морбидным ожирением является синдром сонного апноэ}

амбулаторных условиях в течение по крайней мере 30 дней. В настоящее время нет единого протокола профилактики ТЭЛА в бариатрической хирургии, авторы используют нефракционированный гепарин, низкомолекулярные гепарины в разных дозах. С равной степенью эффективности применяются нефракционированный гепарин по 5 000-7 500 ед. подкожно через 8 ч, внутривенная инфузия гепарина 400 ед. в час, подкожное введение надропарина 0,3-0,6 через 12 ч, эноксапарина 30-40 мг 1-2 раза в сутки [59], дальтепарина по схеме: 2500 ед. подкожно перед операцией и по 5000 ед. подкожно в течение недели после лапароскопических операций, и в течение 3 недель после открытых [22]. Эластическая компрессия ног является обязательным дополнительным фактором профилактики венозного тромбоэмболизма.

\section{ОЖИРЕНИЕ И ФАРМАКОКИНЕТИКА} АНЕСТЕЗИОЛОГИЧЕСКИХ ПРЕПАРАТОВ

Фармакокинетический профиль анестезиологических препаратов может изменяться в зависимости от особенностей абсорбции, распределения и элиминации, обусловленных ожирением.

Абсорбция препаратов, принимаемых внутрь, как правило, не изменена, по сравнению с пациентами с нормальной массой тела. Абсорбция препаратов, доставляемых парентерально, зависит от системной гемодинамики и особенностей регионарного кровообращения. Жировая ткань получает всего 5\% сердечного выброса, внутренние органы - 73\% и тощая ткань - 22\%. Очевидно, что при прогрессировании ожирения и появлении признаков сердечной недостаточности регионарная перфузия ухудшается. Объем распределения препаратов определяется содержанием общей воды, величиной сердечного выброса и объемом циркулирующей крови. Сердечный выброс и объем циркулирующей крови у больных с ожирением, как правило, повышены, а содержание воды снижено, что обусловлено низким содержанием ее в жировой ткани, составляющей значимую долю в общей массе тела. 
Очевидно, что липофильные средства будут иметь большой объем распределения и длительную элиминацию в отличие от гидрофильных. Эффекты препаратов определяются величиной их свободной фракции в плазме. При ожирении отмечаются высокие плазменные концентрации триглицеридов, холестерина, свободных жирных кислот. В этих условиях снижается связь плазменных белков с лекарствами, в результате чего может существенно повыситься их свободная фракция с непрогнозируемым усилением эффекта. С другой стороны, при ожирении в плазме повышен уровень кислого a1-гликопротеина, повышающего аффинитет плазменных белков к препаратам. Таким образом, вероятно, концентрация препаратов, не связанных с протеинами, не будет отличаться от таковой у пациентов с нормальной массой тела [24]. Элиминация препаратов зависит от функционального состояния печени, почек, в известной мере легких. По мере прогрессирования ожирения нарастает жировая дегенерация печени, развивается жировой гепатоз, возможно, цирроз, потенциально снижающие клиренс препаратов с преимущественно печеночным метаболизмом. У пациентов без признаков цирроза и жирового гепатоза печеночный клиренс нормальный или даже повышенный, по сравнению с таковым у людей с нормальной массой тела [10]. Почечный кровоток и гломерулярная фильтрация у больных с ожирением повышены, клиренс креатинина нормальный или высокий, однако при прогрессировании ожирения и коморбидных состояний, в т. ч. сахарного диабета, может развиться почечная дисфункция со снижением клиренса креатинина [21].

Пропофол - наиболее широко применяемый для индукции и поддержания анестезии внутривенный анестетик. Сравнение фармакокинетики пропофола у больных с ожирением и нормальной массой тела выявило одинаковый объем распределения и клиренс препарата. Период полувыведения был также сравним, не было отмечено признаков аккумулирования препарата и пролонгирования его действия у пациентов с ожирением [64]. При расчете дозы препарата для индукции или поддержания анестезии следует пользоваться показателем актуальной массы тела. Во избежание эпизодов нексанкционированного пробуждения, а также излишней нагрузки пропофолом с риском депрессии сердечнососудистой системы целесообразно регистрировать величину BIS-индекса, оценивающего уровень седации и позволяющего поддерживать ее на оптимальном уровне.

Бензодиазепины - препараты, широко применяемые для премедикации, седации, в определенных ситуациях - для индукции в анестезию и ее поддержания. Бензодиазепины высоко липофильны, их объем распределения существенно зависит от количества жира в организме. Мидазолам, наиболее востребованный в анестезиологической практике бензодиазепин, демонстрирует изменение фармакокинетики у больных с ожирением, по сравнению с пациентами с нормальной массой тела. Объем его распределения в 3 раза больше при ожирении, а период полувыведения при использовании одинаковых доз у больных с ожирением составляет более 8 ч, тогда как у субъектов с нормальной массой тела менее 3 [31]. При этом клиренс препарата не зависит от массы тела. Таким образом, применяя у больных с ожирением мидазолам, а другие бензодиазепины в большей степени, следует предвидеть возможность их пролонгированного седативного действия, способного ухудшить условия для оптимальной послеоперационной реабилитации.

Современный ингаляционный анестетик севофлюран обладает низкой растворимостью в тканях, в т. ч. жировой. Время насыщения тканей и время элиминации препарата после прекращения его подачи у больных с ожирением и с нормальной массой тела практически идентичны, что делает препарат безусловно показанным к применению в бариатрической анестезиологии [46].

\section{Риск тромбоза глубоких вен ног и ТЭЛА у пациентов в бариатрической хирургии вдвое превышает аналогичный риск у больных с нормальной массой тела}

Не следует сбрасывать со счетов старейший анестезиологический препарат закись азота. У больных с морбидным ожирением, демонстрирующим склонность к гипоксемии во время анестезии и операции, нередко возникает необходимость повышать концентрацию кислорода во вдыхаемой смеси до 100\%, что исключает применение закиси азота как компонента ингаляционной анестезии. Кроме того, способность закиси азота диффудировать в различные полости может приводить к вздутию кишечника и ухудшению условий для операции, особенно лапароскопической. Не следует сбрасывать со счетов и эметогенный эффект. Тем не менее закись азота занимает достаточно прочное место в арсенале анестезиолога, в частности и потому, что в сочетании с современным, весьма дорогостоящим севофлюраном способна значимо снизить его минимальную альвеолярную концентрацию (МАК), а следовательно, снизить его расход и стоимость анестезии [5].

Миорелаксанты. Наиболее современными, используемыми в бариатрической анестезиологии средствами этой группы являются цисатракуриум и рокурониум, препараты средней продолжительности действия, недеполяризующего типа. Не следует обходить вниманием и единственный миорелаксант деполяризущего типа действия, сукцинилхолин с ультракороткой продолжительностью эффекта. Сравнение фармакокинетики цисатракуриума у больных с ожирением и нормальной массой тела не выявило различий в скорости элиминации, объеме распределения и величине клиренса. Скорость регресса нейромышечного блока также существенно не отличалась. При расчете дозы препарата принимали во внимание актуальную массу тела. Применение цисатракуриума безусловно показано при наличии у пациента признаков печеночной и почечной недостаточности, т. к. его разрушение носит неферментативный характер (элиминация Хоффмана) $[21,5]$. Изучение действия рокурониума у больных с ожирением и нормальной массой тела не выявило разницы в фармакокинетике и фармакодинамике. Сравнимыми были время распределения, период полувыведения и клиренс пре- 
парата [58]. Препарат является высокоионизированным соединением с малым объемом распределения, в связи с чем при расчете его индукционной и поддерживающих доз целесообразно опираться на величину идеальной массы тела или тощей массы тела, превышающей идеальную у больных с ожирением примерно на 20\%. Препарат метаболизируется в печени и экскретируется с желчью, в связи с чем при выраженной печеночной недостаточности возможно значительное пролонгирование действия. С другой стороны, сегодня рокурониум может быть быстро инактивирован специфическим антагонистом сугаммадексом с полным восстановлением нейромышечной проводимости [5]. Сукцинилхолин занимает довольно прочную позицию в анестезиологическом формуляре пациентов с ожирением и проблемными верхними дыхательными путями, способными создать трудности при прямой ларингоскопии и интубации трахеи. Расчет дозы сукцинилхолина следует проводить исходя из актуальной массы тела. Также следует принять во внимание, что повышение веса пациента сопровождается увеличением активности псевдохолинестеразы плазмы - фермента, разрушающего сукцинилхолин. Вследствие этого действие ультракороткого миорелаксанта может быть еще сокращено, что следует рассматривать как безусловный положительный момент [46].

Опиоиды. Фентанил, единственный, широко применяемый при операционном обезболивании в России синтетический анальгетик, является высоколипофильным средством. Тем не менее он не демонстрирует изменений фармакокинетики у больных с ожирением по сравнению с пациентами с нормальной массой тела [63]. Однако пациенты с ожирением демонстрируют повышенную чувствительность к опиоидам, чреватую развитием депрессии дыхания и гипоксемии на фоне их действия [46]. При расчете дозы фентанила предпочтительнее пользоваться показателем тощей массы тела, нежели актуальной.

Местные анестетики. Фармакокинетика местных анестетиков у пациентов с морбидным ожирением и нормальной массой тела практически идентична [21]. Не следует пренебрегать мнением авторов, утверждающих, что идентичные дозы местного анестетика вызывают более широкую блокаду, в частности эпидуральную, у пациентов с ожирением, чем у больных с нормальным весом [54].

\section{МОНИТОРИНГ В ОПЕРАЦИОННОМ ПЕРИОДЕ}

Залогом безопасности пациента является Гарвардский стандарт мониторинга, предполагающий выполнение ряда обязательных действий:

1) присутствие в операционной анестезиологической бригады;

2) мониторинг параметров вентиляции, оксигенации и кровообращения;

3) проведение капнометрии и оксиметрии;

4) нейромышечный мониторинг;

5) температурный мониторинг;

6) регистрация BIS-индекса с целью оценки глубины седации во время анестезии;
7) регистрация концентрации ингаляционных анестетиков и их минимальной альвеолярной концентрации (МАК);

8) исследование КЩС, газов крови, электролитов, глюкозы, лактата.

Мониторинг позволяет зарегистрировать опасные тенденции или реальные события в состоянии жизненно важных систем пациента и наркозно-дыхательной аппаратуры, провести их целенаправленную и быструю коррекцию. Эффективность различных методик при регистрации опасных интраоперационных инцидентов следующая: пульсовая оксиметрия (SpO2) - 27\%, капнометрия - 24\%, кардиоскопия - 19\%, мониторирование АД - 12\%, системы разгерметизации контура - 8\%, оксиметрия дыхательной смеси - 4\%.

Мониторинг у больных с морбидным ожирением в некоторых позициях может быть сопряжен с определенными трудностями. Регистрация АД неинвазивным методом в стандартном месте бывает затруднительна или невозможна при использовании манжетки обычного размера. Вполне обосновано применение прямого метода регистрации АД через канюлю, установленную в лучевую артерию. Помимо точности тонометрии постоянный доступ в артериальное русло позволяет исследовать газы в артериальной крови и иметь полное представление об индексе оксигенации пациента. Очень важен показатель напряжения $\mathrm{CO}_{2}$ в артериальной крови $\left(\mathrm{paCO}_{2}\right)$, обычно практически равный напряжению $\mathrm{CO}_{2}$ в конце выдоха, регистрируемому капнометром $\left(\mathrm{ETCO}_{2}\right)$. Физиология дыхательной системы пациентов с морбидным ожирением характеризуется высоким внутрилегочным шунтом, возрастающим до 20-25\% во время общей анестезии и ИВЛ. Помимо гипоксемии, эта особенность приводит к большой разнице между $\mathrm{ETCO}_{2}$ и раСО 2 . Напряжение $\mathrm{CO}_{2}$ в артериальной крови, как правило, на 15-20 мм рт. ст. выше, чем в последней порции выдыхаемого воздуха. Но именно на $\mathrm{paCO}_{2}$ следует ориентироваться при проведении ИВЛ и поддержании оптимального для данного пациента напряжения $\mathrm{CO}_{2}$ в крови, имея в виду, что гипокапния в конце операции и анестезии может привести к депрессии спонтанного дыхания, а гиперкапния может вызвать тяжелый респираторный ацидоз, карбонаркоз с депрессией сознания.

Мониторирование темпа мочеотделения через установленный в мочевой пузырь катетер - важный элемент мониторинга, но следует иметь в виду, что при лапароскопических операциях один из эффектов пневмоперитонеума заключается в снижении почечной перфузии и, следовательно, в олигурии. Понимая механизм этого явления, не следует использовать объем выделенной мочи как знак к увеличению темпа инфузионной терапии [19].

\section{АНЕСТЕЗИОЛОГИЧЕСКОЕ ОБЕСПЕЧЕНИЕ}

Проведение любой анестезии требует надежного венозного доступа. Предпочтение следует отдавать дистальным сосудам, расположенным на тыльной поверхности кисти. Для профилактики катетерной инфекции необходимо применять специальные фиксационные повязки, препятствующие движению катетера в вене и инфицированию места пункции. 
Крупные операции, такие как открытые билиопанкреатические шунтирования с резекцией желудка, как правило, требуют доступа в центральную вену для проведения более агрессивной инфузионной терапии, парентерального питания. Оптимальным доступом является правая внутренняя яремная вена, через которую катетер легко устанавливается в верхнюю полую вену. Толстая шея не является непреодолимым препятствием. Ультразвуковой аппарат может существенно облегчить поиск вены и повысить успех ее катетеризации. Не стоит исключать из арсенала катетеризацию подключичной вены, но следует иметь в виду, что катетер нередко устанавливается в неверную позицию, например в наружную или внутреннюю яремные вены, что приводит к тромбозам [6]. Преодолеть это возможно при использовании рентгеноскопического контроля или специального адаптера Certodyn.

\section{ПРЕМЕДИКАЦИЯ}

Во избежание развития глубокой гипотензии во время индукции и при поддержании анестезии в день вмешательства необходимо отменить прием ингибиторов АПФ и ингибиторов рецепторов ангиотензина II. И хотя b-блокаторы также способны привести к гипотензии при анестезии, принимается во внимание их протективный миокардиальный эффект. Их прием, возможно, в сниженной дозировке, целесообразно продолжить утром в день операции. Статины обладают миотоксическим эффектом, в связи с чем при обширных бариатрических операциях могут способствовать развитию специфического для бариатрической хирургии осложнения - рабдомиолиза. В этих случаях прием статинов необходимо прекратить. Не следует принимать в день операции и сахароснижающие препараты. Гликемия корригируется простым инсулином под постоянным контролем уровня глюкозы в крови.

Профилактика возможного кислотно-аспиращионного синдрома. У больных с морбидным ожирением, даже натощак, в желудке имеется больший, чем у пациентов с нормальным весом, объем содержимого с низким рН. В сочетании с высоким интраабдоминальным давлением, грыжами пищеводного отверстия диафрагмы эти факторы могут приводить к развитию кислотно-аспирационного синдрома [33]. На этом основании в схему премедикации рекомендовано включать прокинетики и блокаторы кислотообразования. Однако дальнейшие исследования этой темы показали, что через 8 ч голодания объем и кислотность желудочного содержимого больных с морбидным ожирением и с нормальной массой тела практически идентичны. Не подтверждается более высокая частота развития кислотно-аспирационного синдрома у больных с ожирением [43]. С этих позиций вышеописанные профилактические меры необязательны.

Больные с ожирением, как правило, хорошо мотивированы к оперативному лечению, направленному на снижение массы тела, но страх перед операцией и анестезией - вполне естественные эмоции, поэтому анксиолитический аспект премедикации очень важен. Оптимальным анксилитиком, с лучшими фармакокинетическими и фармакодинамическими качествами, хорошей прогнозируемостью эффекта является мидазолам (дормикум). И если основной способ его введения в качестве средства премедикации в общехирургической практике - внутримышечный, то в бариатрической хирургии этот путь введения лекарств не должен рассматриваться как перспективный, ибо никогда нет уверенности, что игла для внутримышечных инъекций преодолела подкожно-жировую клетчатку. Следовательно, эффект препарата будет непрогнозируем. Внутривенное введение мидазолама может вызвать слишком глубокую седацию, нарушив респираторное равновесие и лишив пациента необходимой мобильности. Мидазолам обладает высокой биодоступностью при приеме внутрь, создавая при этом достаточно поверхностный, безопасный анксиолизис. Оптимальной дозой мидазолама при приеме внутрь за 30-40 мин до операции является 0,1 мг/кг ИМТ (идеальной массы тела). При всей «мягкости» седативного эффекта мидазолама при пероральном приеме у значительной группы больных с ожирением следует отказаться от премедикации. В эту группу входят больные с синдромом сонного апноэ, гиповентиляционным синдромом, характеризующиеся повышенной чувствительностью к депрессивным эффектам бензодиазепинов, опиоидов, общих анестетиков.

\section{Больные с ожирением, как правило, хорошо мотивированы к оперативному лечению, направленному на снижение массы тела, но страх перед операцией и анестезией - вполне естественные эмоции, поэтому анксиолитический аспект премедикации очень важен}

Позищи пащиента с ожирением на операционном столе - проблема, имеющая, как минимум, два аспекта.

Первый заключается в высоком риске развития неврологических и мышечных осложнений при длительной иммобилизации на операционном столе. В послеоперационном периоде нередко выявляются признаки полинейропатий в виде парестезий, онемения, моторных нарушений, особенно в зоне иннервации плечевого и пояснично-крестцового сплетений. Длительное давление определенных групп мышц на операционный стол может привести к рабдомиолизу. Профилактика этих осложнений заключается в применении специальных подушек, прокладок, располагаемых под выступающие части тела и возможном сокращении времени операции с быстрой активизацией пациентов в послеоперационном периоде [27]. По возможности время операции следует ограничить 5 ч, при необходимости пролонгирования вмешательства следует рассмотреть вопрос о разделении операции на этапы.

Второй аспект позиционирования на операционном столе обусловлен тем, что в горизонтальном положении на спине у больных с ожирением повышается интраабдоминальное давление, ухудшается подвижность диафрагмы, снижается компрометированная исходно, жизненная емкость легких, нарастает внутрилегочное шунтирование, развивается выраженная гипоксемия, способная привести у наиболее тяжелых больных к развитию «синдрома смерти при ожирении» в горизон- 
тальном положении [68]. Компрессия нижней полой вены в положении на спине может привести к развитию синдрома низкого сердечного выброса, похожего на синдром аортокавальной компрессии в акушерской клинике. При адекватной преоксигенации перед вводным наркозом время безопасного периода апноэ (до снижения $\mathrm{SaO}_{2}$ до 85\%) при горизонтальном положении на спине составляет $123 \pm 24$ сек. Аналогичный показатель при обратном положении Тренделенбурга составляет $178 \pm 55$ сек., при положении с приподнятым головным концом $-153 \pm 63$. Время восстановления оксигенации артериальной крови до исходного уровня составляет соответственно 206, 80 и 97 сек. [46]. Очевидно, что именно обратное положение Тренделенбурга оптимально с точки зрения профилактики глубокой гипоксемии при индукции в анестезию и в течение операции и анестезии.

Помимо общей позиции тела на операционном столе специальная позиция головы и верхней части грудной клетки применяются для улучшения условий ларингоскопии и интубации трахеи. Под верхнюю часть грудной клетки и головы подкладываются подушки. Создаваемая позиция называется «head elevated laryngoscopy position - HELP», она обеспечивает менышее легочное сопротивление, улучшает условия масочной вентиляции, ларингоскопии и интубации трахеи [19].

Индукция в анестезию. Преоксигенация 100\% кислородом всегда предшествует индукции. Этот маневр увеличивает время возможного безопасного апноэ, обеспечивает денитрогенизацию альвеол и эффективное насыщение организма ингаляционным анестетиком по завершении индукции [5]. Наиболее применимые средства индукции в анестезию - фентанил, пропофол и миорелаксант. В определенных ситуациях, когда имеются реальные опасения трудной интубации трахеи, целесообразно провести индукцию севофлюраном с сохранением спонтанного дыхания. По достижении достаточной глубины анестезии можно провести пробную ларингоскопию для определения дальнейшей тактики. При достаточной визуализации голосовой щели можно ввести миорелаксант и выполнить интубацию трахеи. При невозможности визуализировать голосовую щель можно прибегнуть к помощи фибробронхоскопа, при этом сохраняющееся спонтанное дыхание предоставляет определенный резерв времени. Второй вариант - вывести пациента из анестезии, прекратив ингаляцию севофлюрана, и выполнить интубацию трахеи при ясном сознании и спонтанном дыхании с помощью фибробронхоскопа.

Выбор миорелаксанта для индукции следует провести между деполяризующим препаратом короткого действия сукцинилхолином и недеполяризующими препаратами средней продолжительности действия - рокурониумом и цисатракуриумом. В случае затруднительной масочной вентиляции во время индукции и предполагаемой трудной интубации трахей целесообразно воспользоваться сукцинилхолином в дозе 2 мг/ кг актуальной массы тела. Действие препарата прекращается в течение 5 мин, и при неудачной интубации трахеи довольно быстро можно вывести пациента из анестезии и прибегнуть к альтернативным методикам интубации трахеи. Представляется, что применение рокурониума во время индукции удобнее, чем цисатракуриума, ввиду его более быстрого действия. Уже через 1,5-2 мин после введения 0,6-0,9 мг/кг идеальной или тощей массы тела возможно выполнить интубацию трахеи. Аналогичное действие на фоне применения цисатракуриума в дозе 0,1-0,15 мг/кг актуальной массы тела возможно не менее, чем через 4 мин. Стратегически применение рокурониума в бариатрической анестезиологии более оправданно, т. к. имеется его антидот сугаммадекс, способный полностью устранить нейромышечный блок с восстановлением спонтанного дыхания на любом этапе анестезии, в т. ч. во время индукции в наркоз и неудающейся интубации трахеи.

Стратегия вентиляции. Уже на этапе индукции в анестезию у больных с морбидным ожирением развивается подчас весьма выраженная гипоксемия и гиперкапния, обусловленные особенностями физиологии дыхательной системы этой категории пациентов, в основе которой лежит нарастание внутрилегочного шунтирования и ателектазирования ниже расположенных участков легких $[65,46]$. В рутинных случаях при нарастании гипоксемии и гиперкапнии анестезиолог увеличивает дыхательный объем и минутную вентиляцию легких, однако у больных с ожирением подобные действия чреваты выраженным повышением пикового давления на вдохе и развитием вентилятор-ассоциированной травмой легких, что может лишь усугубить сложную ситуацию [44]. Увеличение $\mathrm{FiO}_{2}$ до 1,0 для коррекции гипоксемии также должно проводиться с осторожностью и ограничением во времени, имея в виду, что гипероксия дыхательной смеси способствует усилению ателектазирования. Наркозно-дыхательный аппарат должен быть способен осуществлять ИВЛ как по заданному объему, так и по давлению. Для профилактики ателектазирования легких уже на этапе вводного наркоза необходимо создавать положительное давление в конце выдоха (ПДКВ), во избежание развития резорбционных ателектазов не следует превышать $\mathrm{FiO}_{2}>0,8$. Ограничение дыхательного объема 7-10 мл/кг ИМТ предупреждает легкие от перерастяжения и баротравмы. Конечное положительное давление на вдохе необходимо поддерживать на уровне не выше 30 см вод. ст., для чего необходимо маневрировать различными методиками вентиляции, соотношением продолжительности вдоха и выдоха, созданием плато на вдохе или его исключением. При необходимости возможно поддержание контролируемой умеренной гиперкапнии. Во время анестезии необходимо поддерживать ПДКВ в пределах 8-12 см вод. ст. При развитии тяжелой гипоксемии вследствие ателектазирования легких может потребоваться проведение «рекруитмент маневра», заключающегося в создании пикового давления на вдохе $\geq 40$ см вод. ст. и ПДКВ 12-15 см вод. ст. в течение 10-12 сек. [19] с периодическим его повторением, при необходимости в ходе анестезии. Маневр небезопасен, чреват развитием баротравмы легких и гемодинамической нестабильностью.

\section{ПОДДЕРЖАНИЕ АНЕСТЕЗИИ}

В большой абдоминальной хирургии «золотым стандартом» обезболивания является комбинированная эпидуральная анестезия, под которой следует понимать грудную эпиду- 
ральную анестезию в сочетании с поверхностной общей анестезией современными ингаляционными анестетиками, в частности севофлюраном, или тотальной внутривенной анестезией пропофолом [76] с ИВЛ на фоне миорелаксации рокурониумом или цисатракуриумом. Именно такой вид анестезии обеспечивает наилучшее обезболивание, антистрессовую защиту и быструю постнаркозную реабилитацию $[12,53]$. Пролонгирование эпидуральной анальгезии в послеоперационном периоде сопровождается наиболее полным обезболиванием, хорошим самочувствием, ранним разрешением пареза кишечника и возможностью начала естественного питания. Весьма важным обстоятельством является возможность избежать продленной ИВЛ в послеоперационном периоде [35]. Применение эпидуральной анестезии в качестве компонента анестезиологического пособия при крупных абдоминальных операциях сопровождается снижением частоты венозного тромбоэмболизма, пневмоний, инфарктов миокарда, острой почечной недостаточности и летальности. При операциях менее травматичных, чем открытое билиопанкреатическое шунтирование, таких как лапароскопическое бандажирование желудка или лапароскопическая продольная резекция желудка, вариант комбинированной эпидуральной анестезии не является методом выбора, оптимальной методикой признан эндотрахеальный наркоз современными ингаляционными анестетиками, такими как севофлюран и дезфлюран [19].

\section{Выбор миорелаксанта для индукции следует провести между деполяризующим препаратом короткого действия сукцинилхолином и недеполяризующими препаратами средней продолжительности действия - рокурониумом и цисатракуриумом}

Разумеется, у пациентов с морбидным ожирением возникают специфические проблемы при выполнении пункции и катетеризации эпидурального пространства:

1) отсутствие видимых и пальпируемых анатомических ориентиров;

2) невозможность нормального позиционирования больного

3) необходимость использования нестандартного расходного материала и специальных методик.

Создать оптимальную позицию для верификации зоны пункции также сложно из-за размеров живота. Естественно, в положении лежа эти условия обеспечить еще труднее, поэтому пункция и катетеризация эпидурального пространства у больных с ожирением должна производиться в положении сидя. Актуальны наборы для эпидуральной анестезии с иглами 110 мм и 120 мм. Наш опыт применения эпидуральной анестезии у пациентов с морбидным ожирением свидетельствует, что в 86\% случаев расстояние от кожи до эпидурального пространства на среднегрудном уровне $\mathrm{Th}_{6}-\mathrm{Th}_{7}-\mathrm{Th}_{8}$ превышало 8 см (в среднем 10,0 \pm 0,60 cм). Это расстояние у людей с нормальной массой тела составляет 5-7 см.
Тактика интраоперационного применения эпидуральной анестезии при операциях билиопанкреатического шунтирования. Тест-дозу лидокаина 2\%-4,0 вводим после начала внутривенной инфузии жидкости на операционном столе. Через 5-6 мин при отсутствии признаков спинальной блокады приступаем к введению основной дозы местного анестетика. В случае применения в качестве тест-дозы 0,75\%-3,0 ропивакаина период наблюдения, в течение которого может развиться спинальная блокада, увеличивается до 10-11 мин. Убедившись в отсутствии признаков спинальной анестезии, можно приступить к вводному наркозу и параллельному введению основной дозы местного анестетика в эпидуральное пространство. Оптимальным местным анестетиком для эпидуральной анестезии является ропивакаин.

Вопрос дозирования местного анестетика во время операции в настоящее время не имеет строгого научного подтверждения. Нет данных об объеме препарата, необходимом для блокады одного сегмента.

Основную дозу ропивакаина 0,5-0,75\% следует вводить дробно по 3,0-4,0 с интервалами 10 мин до достижения объема 10,0-13,0, выбранного эмпирически и, по-видимому, близкого к реально необходимому для обеспечения сенсорной и симпатической блокады в зоне иннервации брюшной полости $\mathrm{Th}_{4}-\mathrm{Th}_{12}-\mathrm{L}_{1}$. Пошаговое, дробное введение ропивакаина профилактирует развитие быстрой грудной симпатической блокады, чреватой гипотензией, усугубляемой средствами для вводного наркоза. С учетом фармакокинетики ропивакаина и длительности латентного периода вызываемой им блокады [49] повторную дозу препарата в объеме 75\% основной необходимо вводить через 2,5 ч после завершения пошагового введения основной дозы. Фармакокинетика местных анестетиков у пациентов с морбидным ожирением и нормальной массой тела практически идентична [31]. Не следует пренебрегать мнением авторов, представляющих данные, что идентичные дозы местного анестетика вызывают более высокий уровень эпидуральной блокады у пациентов с ожирением, чем у больных с нормальным весом [36, 48].

Введение в эпидуральное пространство фентанила 100 мкг до начала хирургического вмешательства и за 30-40 мин до его окончания существенно улучшает анальгетический потенциал эпидуральной блокады.

Применение комбинированной грудной эпидуральной анестезии позволяет поддерживать достаточно поверхностный уровень общей анестезии, оптимизируемый с помощью мониторинга BIS-индекса, поддерживаемого на уровне 40-60. Концентрация севофлюрана, необходимая для такой глубины анестезии, обычно составляет 1 МАК, а средние дозы фентанила не превышают 1 мкг/кгАМТ/ч, что позволяет избежать опиоидной депрессии дыхания в конце операции [8].

Неудача при выполнении эпидуральной блокады, отказ пациента или наличие к ней противопоказаний предполагают проведение анестезиологической защиты методом эндотрахеального наркоза севофлюраном, фентанилом, рокурониумом или цисатракуриумом. Естественно, в отсутствие нейроаксиальной блокады требуется существенно большая доза опиоидного анальгетика фентанила. Наш опыт свиде- 
тельствует, что доза фентанила 2,0-2,5 мкг/кгАМТ/ч достаточна для поддержания адекватной анестезии [8].

Разумное снижение нагрузки опиоидами - важный аспект быстрой постнаркозной реабилитации больных с морбидным ожирением. Фентанил - липофильный опиоид, характеризуется повышенным объемом распределения и пролонгированным периодом полувыведения у больных с морбидным ожирением, по сравнению с пациентами с нормальной массой тела [15]. Снижение чувствительности дыхательного центра к $\mathrm{CO}_{2}$ на фоне действия опиоидов - характерная особенность больных с ожирением [21]. Примененные нами дозы существенно ниже рекомендуемых [1] как в группе пациентов, оперированных в условиях комбинированной эпидуральной анестезии, так и в группе, где эпидуральную анестезию не использовали. Достаточность анальгетического компонента определяли, ориентируясь на стабильность показателей АД, ЧСС, BIS, отсутствие таких клинических признаков, как потливость, саливация, покраснение лица.

Проведение комбинированной грудной эпидуральной анестезии, особенно при использовании ропивакаина в средних и высоких концентрациях (0,5-0,75\%), может сопровождаться развитием гипотензии. Как правило, пациенты с морбидным ожирением характеризуются стабильностью гемодинамики в условиях нейроаксиальной блокады в связи с особенностями физиологии сердечно-сосудистой системы, заключающимися в гиперволемии, повышенном минутном объеме кровообращения, увеличенном объеме спланхнического кровотока $[10,41]$. Тем не менее всегда должна быть предусмотрена возможность терапии гипотензии эфедрином, титруемым по 5-10 мг.

У пациентов с рядом коморбидных состояний (ИБС, гипертоническая болезнь) гипотензия, развивающаяся вследствие фармакологической симпатэктомии, весьма небезопасна. Преследуя цели эффективной нейроаксиальной интраоперационной защиты и профилактики нарушения системной гемодинамики у пациентов данной группы, целесообразно проведение интраоперационной нейроаксиальной «анальгезии» смесью 0,2\% ропивакаина в сочетании с фентанилом 2 мкг/мл и адреналином 2 мкг/мл. Подобная тактика хорошо зарекомендовала себя у онкологических больных при обширных абдоминальных и торакоабдоминальных операциях [3]. Инфузию смеси 0,2\% ропивакаина с адъювантами начинают после введения тест-дозы и периода наблюдения, необходимого для исключения развития спинальной блокады. Скорость инфузии анальгетической смеси на уровне 8,0-10,0/ч с продолжением в этом же режиме в послеоперационном периоде. Улучшение анальгетического потенциала ропивакаина при комбинации его с опиоидами (фентанилом) и адреналином, обладающими антиноцицептивными возможностями, было продемонстрировано Niemi G. et Bravik Н. в большой торакальной и абдоминальной хирургии [52].

Время пробуждения пациентов после окончания операции при проведении эндотрахеального наркоза севофлюраном, вне зависимости от применения эпидуральной анестезии и несмотря на разные дозы фентанила, практически не отличалось. Все пациенты были экстубированы в течение 10-15 мин после завершения операции [8]. Ни в одном случае не потребовалась продленная искусственная вентиляция легких, являющаяся существенным фактором риска у больных с морбидным ожирением. Проведение искусственной вентиляции легких в послеоперационном периоде, обусловленное сохраняющейся депрессией сознания и дыхания, сопровождается возрастанием частоты легочных и тромбоэмболических осложнений [35]. Еще более быструю постнаркозную реабилитацию при операциях гастрошунтирования продемонстрировали авторы, применившие комбинированную эпидуральную анестезию в сочетании с пропофолом 2-3 мг/кг/ч, поддерживая BIS в пределах 60 [53]. Спонтанное дыхание восстанавливалось через $4 \pm 3$ мин, экстубацию проводили через $8 \pm 3$ мин.

Следует отметить важное отличие. При использовании эпидуральной анестезии в качестве компонента анестезиологического пособия уровень болевых ощущений при пробуждении стремился к нулю по визуально-аналоговой шкале (ВАШ), тогда как без применения нейроаксиальной блокады уровень боли соответствовал 30-40 по ВАШ. Уровень анальгезии с болевыми ощущениями <30 можно считать оптимальным [7]. Повышение уровня анальгезии в первые послеоперационные часы может быть достигнуто с помощью надапоневротической инфильтрации послеоперационной раны при ее ушивании ропивакаином 0,2\% в максимально возможной разовой дозе 220 мг $(110,0)$.

Важным аспектом быстрой и эффективной постанестетической реабилитации является полное восстановление нейромышечной проводимости. Традиционно на завершающем этапе анестезии для устранения остаточного действия миорелаксантов применяются антихолинэстеразные препараты, обладающие такими общеизвестными побочными әффектами, как нарушения ритма сердца, гиперсаливация, повышение частоты послеоперационной тошноты и рвоты, увеличение вероятности ларингоспазма. Исследование нейромышечной проводимости демонстрирует далеко не полное ее восстановление, что чревато серьезными респираторными осложнениями. В настоящее время в распоряжении анестезиологов имеется современный препарат сугаммадекс, являющийся специфическим антагонистом стероидных миорелаксантов (рокурониум, векурониум). Введение препарата на завершающем этапе анестезии в дозе 2 мг/кг полностью устраняет нейромышечную блокаду без каких-либо побочных эффектов. Сугаммадекс может быть применен и в случае неудающейся интубации трахеи. Введение антагониста в дозе 16 мг/кг полностью устраняет глубокий нейромышечный блок, вызванный рокурониумом, и в течение 1,5-2 мин восстанавливает спонтанное дыхание [4]. Применение сугаммадекса при лапароскопических гастрошунтированиях (1 500 операций) в дозе 2-4 мг/кг при выходе из анестезии привело к устранению респираторных осложнений. При аналогичных операциях такой же численности, выполненных до 2009 г., когда сугаммадекса не было в клинической практике, было отмечено 9 случаев острой дыхательной недостаточности вследствие развития ателектазов, карбонаркоза, продленной ИВЛ [48]. Сугаммадекс, безусловно, облегчает и ускоряет экстубацию трахеи в операционной [42]. 


\section{НЕКОТОРЫЕ ПРОБЛЕМЫ ПОСЛЕОПЕРАЦИОННОГО ПЕРИОДА}

Несмотря на особенности физиологии и наличие многих коморбидных состояний, анализ информации свидетельствует: нет разницы в частоте послеоперационных осложнений у больных с ИМТ $<30 \mathrm{\kappa r} / \mathrm{M}^{2}$, ИМТ $=30-34,9$ кг $/ \mathrm{M}^{2}$ и ИМТ $>35$ кг/ $\mathrm{M}^{2}$ [25]. Тем не менее у больных с морбидным ожирением имеются специфические послеоперационные проблемы, на которые необходимо обратить внимание.

Очень важно обеспечить нахождение пациента в позиции, обеспечивающей максимально лучшую оксигенацию в послеоперационном периоде. Уже на этапе экстубации необходимо поднять головной конец стола на $30-35^{\circ}$ и поддерживать позицию с поднятым головным концом или полулежа. Во избежание травмы плечевых сплетений и развития пареза рук важно удобное, приведенное к телу положение рук с использованием подушек.

Для оптимизации респираторных функций в ближайшие послеоперационные часы больным с морбидным ожирением, а пациентам с синдромом сонного апноэ и в дальнейшем, показано проведение вспомогательной неинвазивной вентиляции легких. Опасения несостоятельности желудочных швов и анастомозов при проведении неинвазивной масочной вентиляции с постоянным повышенным давлением в дыхательных путях (СРАР, ВіРАР) и возможной аэрофагии не получили подтверждения [45, 74]. Не было отмечено клинически значимого повышения давления внутри желудочно-кишечной трубки и напряжения в стенке желудка в зоне расположения швов. Также авторы не отметили увеличения частоты послеоперационной тошноты и рвоты на фоне применения СРАР и ВіРАР.

Тошнота и рвота - серьезные послеоперационные осложнения, но ожирение как таковое не является важным фактором их развития [19]. Введение в схему премедикации дексаметазона в дозе 4-8 мг и применение ондансетрона в дозе 4-8 мг на завершающем этапе анестезии позволяет снизить частоту развития этого неприятного и небезопасного осложнения [50].

Трудности послеоперащионной анальгезии и послеопераиионной реабилитащии - следуюшие важные аспекты послеоперащионного периода.

Во-первых, у больных с ожирением, подвергающихся бариатрическим операциям, снижена потребность в анальгетиках, по сравнению с пациентами с нормальным весом. Во-вторых, стандартное применение препаратов группы НПВП может усугубить нефропатию, особенно в случае развития выраженного интраоперационного рабдомиолиза. В-третьих, внутривенное введение парацетамола сопровождается повышенным его клиренсом, вследствие чего в ближайшем послеоперационном периоде целесообразно применять по 1 г 5 раз в сутки вместо традиционных 4. B-четвертых, применяя для послеоперационного обезболивания опиоиды, следует опасаться усугубления гипоксии и гиперкапнии, особенно у пациентов, страдающих синдромом сонного апноэ и гиповентиляционным синдромом, увеличения числа респираторных осложнений. В-пятых, применение наиболее эффективных центральных нейроакси- альных блокад, в частности грудных эпидуральных, сопряжено с техническими трудностями при выполнении и высокой частотой неудач ввиду анатомических особенностей [15].

Тем не менее, принимая во внимание все риски и воплощая в жизнь принципы мультимодальной анальгезии, можно достичь хорошего уровня послеоперационного обезболивания, применяя современные высокотехнологичные методики послеоперационного обезболивания.

Эпидуральная анальгезия является логическим продолжением комбинированной грудной эпидуральной анестезии, проводимой интраоперационно. Эпидуральную анальгезию следует продолжить сразу по поступлении пациентов в отделение интенсивной терапии. Анальгетическая смесь состоит из ропивакаина $0,2 \%$, фентанила в концентрации 2 мкг/мл и адреналина в концентрации 2 мкг/мл. Скорость инфузии устанавливается методом «клинического титрования» и варьирует в пределах 7-14 мл/ч, продолжительность инфузии не менее 72 ч. Во избежание ортостатических реакций при активизации больных, риск которых на фоне нейроаксиальной анальгезии и грудной симпатической блокады повышен, целесообразно тщательно котролировать волемический статус пациентов, не допуская гиповолемии. Поскольку в формировании ноцицептивных импульсов принимают участие не только нервные структуры, но и гуморальные факторы, то сегментарную, даже высокоэффективную, эпидуральную анальгезию необходимо сочетать со средствами системной терапии острой послеоперационной боли. Препараты первой линии - НПВС и парацетамол. Учитывая ульцерогенный эффект НПВС, целесообразно ограничить время их использования 3-4 днями послеоперационного периода и сочетать с применением ингибиторов протонной помпы.

\section{Эпидуральная анальгезия является логическим продолжением комбинированной грудной эпидуральной анестезии, проводимой интраоперационно}

При лапароскопических операциях, когда применение эпидуральной анестезии не является необходимым элементом анестезиологического пособия, инфильтрация портов раствором местного анестетика (ропивакаин 0,5\%) существенно улучшает анальгезию в первые послеоперационные часы.

Внутривенная, контролируемая пащиентом анальгезия опиоидами (КПА). Ввиду повышенного риска развития депрессии дыхания у больных с морбидным ожирением, особенно при наличии синдрома сонного апноэ, целесообразно отказаться от использования длительно действующего и очень эметогенного морфина, сделав ставку на короткодействующий фентанил. Мы располагаем определенным опытом применения КПА фентанилом [8]. Доставку опиоида осуществляем шприцевым дозатором Compact fm с блоком КПА. Режим дозирования: болюс 30 мкг, локаут-интервал 10-12 мин, скорость постоянной инфузии 10 мкг/ч. Длительность проведения КПА после операций билиопанкреатического шунтирования, как правило, составляет 3-4 сут. Опираясь на принципы 
мультимодальной послеоперационной анальгезии, КПА комбинируем с внутривенным введением перфалгана в дозе 4-5 г в сут. в течение 4-5 дней и внутримышечным введением кеторолака 90 мг в сут., или лорноксикама 32 мг в сут. в течение 3-4 дней. Доза фентанила в первые послеоперационные сутки составила 1800 - 200 мкг, во вторые - 1500 - 150 мкг, в третьи и четвертые - 1200 - 250 мкг. Не следует забывать, что при использовании для такого варианта послеоперационной анальгезии необходим пульсоксиметрический мониторинг.

Трансдермальные терапевтические системы (TTC). Стремление к менышей инвазивности, болышей простоте исполнения и хорошей эффективности обратило наше внимание на неинвазивную доставку наркотических анальгетиков с помощью ТТС (пластырей).

Методика применения ТТС. ТТС с содержанием фентанила 8,4 мг и скоростью диффузии 50 мкг/ч апплицируется на свободные от волосяного покрова участки кожи, как правило, в подключичной зоне или в верхней части спины в 21:00-22:00 накануне предстоящей операции. Через 72 ч, по окончании действия ТТС, апплицируется аналогичная ТТС еще на 3 сут. Поскольку послеоперационное обезболивание дожно носить мультимодальный характер, ТТС комбинируется с внутривенным применением парацетамола 4-5 г/сут. и лорноксикама 32 мг/сут. Для улучшения послеоперационной анальгезии, перед ушиванием раны целесообразно выполнить надапоневротическую инфильтрацию ропивакаином 0,2\%-110,0 (220 мг). Применение всех вышеописанных методик послеоперационного обезболивания обеспечивало достаточный уровень анальгезии при активизации пациентов $[8,9]$.

Через 3-5 ч после завершения билиопанкреатического шунтирования - весьма травматичной и длительной операции, все пациенты, независимо от использованной методики послеоперационного обезболивания, были активизированы (стояли, ходили), что свидетельствует о хорошем обезболивающем эффекте всех примененных нами методик послеоперационной анальгезии.

Важным аспектом быстрой послеоперационной реабилитации является профилактика пареза кишечника, и не последнюю роль в этом следует делегировать послеоперационному обезболиванию [38]. Независимо от примененной методики послеоперационного обезболивания шумы перистальтики кишечника выслушивались у всех пациентов утром первых послеоперационных суток. Однако регистрация такого объективного фактора разрешения пареза кишечника, как отхождение газов, происходила существенно позже у пациентов, обезболенных системным введением опиоидов, трансдермально или внутривенно по методике КПА [8].

Мы также наблюдали побочные эффекты при использовании всех методик послеоперационной анальгезии [8]. Тошнота и рвота встречаются достаточно часто, хотя при проведении эпидуральной анальгезии рвота регистрируется существенно реже, чем при использовании ТТС и КПА фентанилом. Из других побочных эффектов эпидуральной анальгезии в 5\% случаев был отмечен кожный зуд, не требовавший проведения специальной терапии. Эпидуральная анальгезия не сопровождалась седацией, эйфорией и депрессией дыхания.
Напротив, применение опиоидных методик послеоперационного обезболивания у части пациентов сопровождалось избыточной седацией, что требует постоянного пульсоксиметрического контроля и при необходимости коррекции программы дозирования фентанила или уменьшения площади ТТС, контактирующей с кожей. Кроме того, должны быть доступны к применению антагонисты $\mu$-опиоидных рецепторов.

Несмотря на эффективность послеоперационой анальгезии фентанилом, применяемым внутривенно или трансдермально, следует помнить об опасности системного применения опиоидов у пациентов с синдромом сонного апноэ. У этого контингента больных с ожирением методом выбора послеоперационной анальгезии является эпидуральная анальгезия, НПВС и парацетамол.

Важным аспектом профилактики респираторных осложнений у больных с морбидным ожирением является применение различных физиотерапевтических приемов, в частности побуждающей спирометрии [19], основная задача которой состоит в расправлении максимального числа альвеол при выполнении максимально возможного вдоха [2]. Помимо восстановления дооперационного объема дыхания методика выполняет функцию мониторинга эффективности дыхания, регистрируя величину максимального вдоха в послеоперационном периоде, сравнение этого параметра с предоперационным уровнем. Снижение спирометрических параметров характерное явление послеоперационного периода. Их депрессия коррелирует с массой тела и возрастанием по мере увеличения ИМТ. Если при нормальном ИМТ лапаротомия вызывает снижение ЖЕЛ на 10\%, то при ИМТ > 30 уже на 40\% [24]. Максимальная редукция ЖЕЛ отмечается в первые часы и сутки после лапаротомии. У больных с ожирением эта динамика носит особенно заметный характер. Снижение ЖЕЛ в послеоперационном периоде менее выражено после проведения операций в условиях комбинированной грудной эпидуральной анестезии. Восстановление спирометрических параметров происходит значительно быстрее при использовании эпидуральной анальгезии, особенно у больных с ожирением.

Для пациентов с морбидным ожирением характерно повышение интраабдоминального давления, коррелирующее с увеличением объема висцерального жира и сагиттальным диаметром живота. Операции билиопанкреатического шунтирования сопровождались достоверным ростом интраабдоминального давления с 12 до 16 см вод. ст. в течение 2 послеоперационных суток $[15,40]$. Влияние методики послеоперационного обезболивания на степень, продолжительность пареза кишечника, а следовательно, на уровень интраабдоминального давления весьма вероятно [38].

Несмотря на более позднее разрешение пареза кишечника при обезболивании ТТС и КПА фентанилом, по сравнению с ЭА, не было отмечено достоверных отличий в уровне интраабдоминального давления в 1-е, 2-е и 3-и послеоперационные сутки вне зависимости от примененной методики послеоперационного обезболивания. Также была отмечена лишь тенденция к возрастанию интраабдо- 
минального давления к 3 послеоперационным суткам по сравнению с исходным фоном. Стабильность интраабдоминального давления в послеоперационном периоде мы расцениваем как безусловно позитивный факт, в основе которого лежит не только эффективное обезболивание, но и ранняя активизация, быстрое начало энтерального питания, адекватная гидратация. Выраженный послеоперационный парез кишечника при исходно высоком интраабдоминальном давлении с большой вероятностью способен реализоваться в интраабдоминальный компартмент-синдром, сопровождающийся аортокавальной компрессией, снижением спланхнического кровотока, перфузии почек, сердечного выброса, развитием острой почечной и острой дыхательной недостаточности $[40,61]$.

\section{Важным аспектом быстрой послеоперационной реабилитации является профилактика пареза кишечника, и не последнюю роль в этом следует делегировать послеоперационному обезболиванию}

В бариатрической хирургии встречается специфическое осложнение - синдром аутораздавливания с развитием рабдомиолиза и острой почечной недостаточности [27]. Наибольшей компрессии и разрушению подвержены поясничные и ягодичные мышцы. Ситуация усугубляется при сопутствующем сахарном диабете, гипертонической болезни, периферических сосудистых расстройствах и физическом статусе по ASA 2 [19]. Основными лабораторными маркерами рабдомиолиза являются миоглобин и креатинфосфокиназа (КФК) плазмы, повышение уровня которой считается наиболее чувствительным тестом и присутствует в 100\% случаев рабдомиолиза [23]. Рабдомиолиз после операций билиопанкреатического шунтирования диагностируется в 0,9-22,7\% случаев [67]. Уровень КФК плазмы 1000 МЕ/Л подтверждает факт рабдомиолиза. В нашей практике у 4 пациентов были зарегистрированы сверхвысокие концентрации КФК плазмы от 23000 до 63000 МЕ/Л. В трех случаях развилась острая почечная недостаточность, потребовавшая применения гемодиафильтрации с положительным исходом. Инциденты почечной недостаточности варьируют в еще более широких пределах, 6-75\% [17], являясь в ряде случаев фатальными. Помимо лабораторной диагностики рабдомиолиза важным показателем развития этого осложнения является количество и качество мочи. Снижение темпа диуреза, появление мочи бурого цвета с мутными включениями подтверждает диагноз.

Профилактика и терапия рабдомиолиза является междисииплинарной проблемой и заключается в выполнении следуюших рекомендащии:

1) использование противопролежневых матрасов в периоперационном периоде;

2) лимитирование времени операции 5 ч;

3) при необходимости - 2-этапная операция;
4) ранняя активизация, через 3-5 ч после завершения операции;

5) агрессивная инфузионная терапия;

6) прекращение терапии статинами;

7) инфузия бикарбоната натрия и маннитола для ощелачивания мочи и выведения миоглобина. Возможно применение небольших доз салуретиков.

Вопрос об агрессивной инфузионной терапии дискуссионен. Увеличение объема инфузионной терапии кристаллами при бариатрических операциях с 15,0 мл/кг до 40,0 мл/кг привело к увеличению количества мочи интраоперационно и в первые послеоперационные сутки, но не повлияло на разницу в уровне КФК и риск развития острой почечной недостаточности [75].

Венозныи тромбоэмболизм. Частота этого грозного осложнения варьирует в широких пределах. Тромбоз глубоких вен у бариатрических пациентов регистрируется в 5,4\% случаев, в 1\% случаев он осложняется тромбоэмболией легочной артерии [11]. Риск развития тромбоза глубоких вен возрастает при наличии сахарного диабета, гиперлипидемии, гипертонической болезни, варикозной болезни ног, предшествующих операциям в малом тазу, венозном тромбоэмболизме в анамнезе, синдроме сонного апноэ с полицитемией, продолжительной операции и длительной иммобилизации в послеоперационном периоде. Профилактика включает раннюю активизацию и выписку из стационара, применение низких доз нефракционированного гепарина или низкомолекулярного гепарина и перемежающуюся пневматическую компрессию ног. Адекватная профилактика способна снизить риск развития тромбоза глубоких вен и тромбоэмболии легочной артерии до 0,4\% [28]. Возможно применение нефракционированного гепарина по 5000 ед. через 8 ч подкожно или эноксапарина 30-40 мг через 12 ч подкожно. Мы в повседневной практике применяем надропарин в дозе 0,3-0,4 через 12 ч подкожно. Начинать введение антикоагулянта целесообразно вечером накануне операции и продолжать в течение 30 дней. При применении нейроаксиальной блокады необходим 12-часовой период между последним введением низкомолекулярного гепарина и катетеризацией эпидурального пространства, а также удаления катетера из эпидурального пространства. После удаления катетера возобновить терапию низкомолекулярным гепарином можно через 12 ч. Несоблюдение этих правил чревато повышением риска развития эпидуральной гематомы [19].

Несмотря на особенности физиологии пациентов с морбидным ожирением, многие анестезиологические проблемы, трудности в хирургии, метаанализ 22 работ (88 051 пациент) не выявил более высокой госпитальной летальности больных с ожирением и морбидным ожирением по сравнению с пациентами с нормальной массой тела [37]. При этом авторы отметили более длительные сроки госпитализации у больных с ожирением.

Полный список литературы вы можете запросить в редакции. 